\title{
How the US Sanctions Are Affecting the Health Research System in Iran?
}

\author{
Mohammad Dehghani, PhD'; Bita Mesgarpour, PharmD, MPH, PhD²; Shahin Akhondzadeh, PhD, FBPhS; Saber Azami-Aghdash, PhD; \\ Reza Ferdousi, $\mathbf{P h D}^{1^{*}}$ \\ 'Department of Health Information Management, School of Management and Medical Informatics, Tabriz University of Medical Sciences, \\ Tabriz, Iran \\ National Institute for Medical Research Development (NIMAD), Tehran, Iran \\ ${ }^{3}$ Psychiatric Research Center, Roozbeh Hospital, Tehran University of Medical Sciences, Tehran, Iran \\ ${ }^{4}$ Tabriz Health Services Management Research Center, Health Management and Safety Promotion Research Institute, Tabriz University of \\ Medical Sciences, Tabriz, Iran
}

\begin{abstract}
Background: In November 2018, the United States withdrew from the Joint Comprehensive Plan of Action (JCPOA), known commonly as the Iran nuclear deal, and imposed severe sanctions on Iran. This study explores the impact of US sanctions in Iran's health research system.

Methods: This phenomenological study interviewed 24 Iranian health science scholars through purposeful sampling to learn about their experiences and thoughts regarding the impact of US sanctions on Iran's health research system.

Results: The impact of sanctions on Iran's health research system were classified into five categories: (a) financial issues, (b) difficulty in supplying laboratory materials and $(c)$ equipment, $(d)$ disruption in international research collaboration and activities, and (e) other issues (e.g., increased stress and workload).

Conclusion: This study indicated that since research centers in Iran are highly dependent on governmental budgets, sanctions have greatly affected the health research system in Iran. Financial and economic problems, restrictions in transferring funds, and the disruption in political and international relations have created many challenges for supplying medical laboratory materials and equipment for medical and health research centers in Iran.

Keywords: Health Research, Iran, Sanctions, The United States

Cite this article as: Dehghani M, Mesgarpour B, Akhondzadeh S, Azami-Aghdash S, Ferdousi R. How the US sanctions are affecting the health research system in Iran? Arch Iran Med. 2021;24(2):101-106. doi: 10.34172/aim.2021.15.
\end{abstract}

Received: September 28, 2020, Accepted: November 8, 2020, ePublished: February 1, 2021

\section{Introduction}

In November 2018, the US government imposed severe sanctions on Iran after unilaterally withdrawing from the Joint Comprehensive Plan of Action (JCPOA) that was registered in the United Nations. ${ }^{1}$ While the $5+1$ Group (US, Russia, China, UK, and France) and Germany reached this agreement after 11 years of consecutive dialogue, the US government withdrew from the JCOPA agreement because it was believed the deal was not in favor of the US national security interests. ${ }^{2}$

Although sanctions are less costly and politically feasible for the implementing country, their effects on the sanctioned country are more detrimental than wars in many cases ${ }^{3}$. The US sanctions against Iran, before and after the JCOPA agreement, have targeted oil, gas, insurances, shipping, banking, and trade affairs, among others. For instance, it has become much more difficult to provide some medications and health care services for Iranian patients. ${ }^{4}$

Some of the challenges caused by the sanctions on
Iran include the rising cost of laboratory materials and equipment, ${ }^{5}$ challenges in providing laboratory materials and equipment, ${ }^{6}$ rejection of scientific papers authored by Iranian scholars, ${ }^{7,8}$ and various cases of restricting Iranian scholars from joining international events. ${ }^{5}$ Sanctions have eliminated the opportunity for international scientific collaborations and participation in international events, which could in turn affect Iran's scientific production and growth. ${ }^{9}$ In accordance with the policies of the US Office of Foreign Assets Control (OFAC), Elsevier (and other publishers) asked its American editors and reviewers not to consider articles submitted by Iranian authors who were affiliated with Iran's government. Since Iranian academics and students are somehow related to the government in terms of regulations, laws, budgets, and student admissions, the OFAC policy has had a negative impact on most Iranian researchers and students.

The current study attempts to obtain a better understanding of the consequences of the US sanctions on Iran's health research system. This study can provide 
valuable insights into how economic and political sanctions can affect a country's scientific and research system.

\section{Materials and Methods}

A phenomenological approach was employed to obtain a profound understanding of the thoughts and experiences of Iranian researchers about the impact of US sanctions on Iran's health research system. Through purposeful sampling, 24 participants at Tabriz University of Medical Sciences were recruited. Participants were research managers, faculty members, postdoctoral researchers, and Ph.D. students. The selection of participants and interviews continued until data saturation was reached.

Semi-structured interviews were conducted in locations that were convenient for the study participants. The interview guideline included three questions: (a) How have the sanctions affected the health research system in Iran? Please explain your thoughts and experiences. (b) Do you have any personal experience about the impact of sanctions on your own research projects? (c) Which research sections have been most affected by sanctions? Each interview lasted between 31 to 47 minutes. The interviews were audio-recorded with the permission of the interviewees, and notes were taken when necessary. Thematic content analysis was used to analyze and identify the patterns (themes) in the interviews. The transcripts were read, primary coding was done, and codes were classified to related classes and themes. Themes were reviewed, re-classified and re-named several times to ensure the reliability and accuracy in the coding process. To increase the accuracy of coding, and validate the participants' responses, the interview transcripts were summarized and returned to the interviewees in order for them to verify the accuracy of their responses and researchers' notes.

Confidential information was removed from transcripts and the study was approved by the 'committee of ethics in research' at Tabriz University of Medical Sciences.

\section{Results}

Seven research managers, six faculty members, four postdoctoral researchers, and seven Ph.D. students of different academic backgrounds and an age range of 27 to 59 years participated in this study. Results indicated that the US sanctions have affected five major areas in Iran's health research system. In other words, the impacts of sanctions on Iran's health research system were classified into five categories: (a) financial issues, $(b)$ difficulty in supplying laboratory materials and $(c)$ equipment, $(d)$ disruption in international research collaboration and activities, and (e) other issues in carrying out research projects (e.g., increased stress and workload) (Figure 1).

\section{A. Financial Issues}

Lack of Research Budget

Sanctions have devalued Iran's national currency and increased inflation in the country. Due to the economic situation in Iran, the government has not been able to increase the health research budget proportional to the extent of the inflation rate. One of the study participants noted that "... I have to buy a substance for 6 million Rails while last year it was two million Rails, and the university is not capable of supporting me financially...”.

Some participants believed that the health research budgets have not increased significantly because the government's priorities have changed during the sanctions period. A participant explained that "...In face of sanctions, I should not expect the government to put research as its top priority; when the welfare and health of the people are in trouble...".

\section{Delays in Research Grant Payments}

There are considerable delays in the payments of health research grants, up to one year in many cases. This can be illustrated in this statement from a study participant who noted that "we have so many delays in the payments of research grants, so that the prices rise again rapidly and we are no longer able to afford to buy materials...".

\section{Problem in Allocating and Transferring Foreign Currency}

The allocation and transfer of foreign currency to 'study abroad programs', 'open access publishing costs', and 'conference registration fees', and 'the payment of students' costs in foreign universities' have faced many challenges. In this regard, a participant emphasized that "currently, the university pays 52\% of the cost of a 'study abroad program', but the time of payment is unknown, and this amount is too little, only a few students may be able afford attend the studying abroad program".

\section{B. Challenges in Supplying Laboratory Materials Trade Restrictions with Foreign Companies}

As a consequence of sanctions, foreign companies are reluctant to sell (medical) laboratory materials to Iranian companies and more concerned about the penalties specified by the US government for doing international trades with Iran. This issue was illustrated by a faculty member as: "it's not beneficial for foreign companies to export laboratory materials to Iran because due to the sanctions, many Iranian companies may not have enough money to purchase those materials...".

\section{Delays in Supplying Laboratory Materials}

Circumventing sanctions through various intermediaries and the increase in the number of brokers in the supply chain have caused the prices of medical laboratory materials to rise sharply. A participant pointed to this issue as: "... Well, we are under sanctions when you want to import a substance to the country, it is almost impossible to buy directly from the main company, and buying from brokers has increased the price and time of access to materials; transferring 


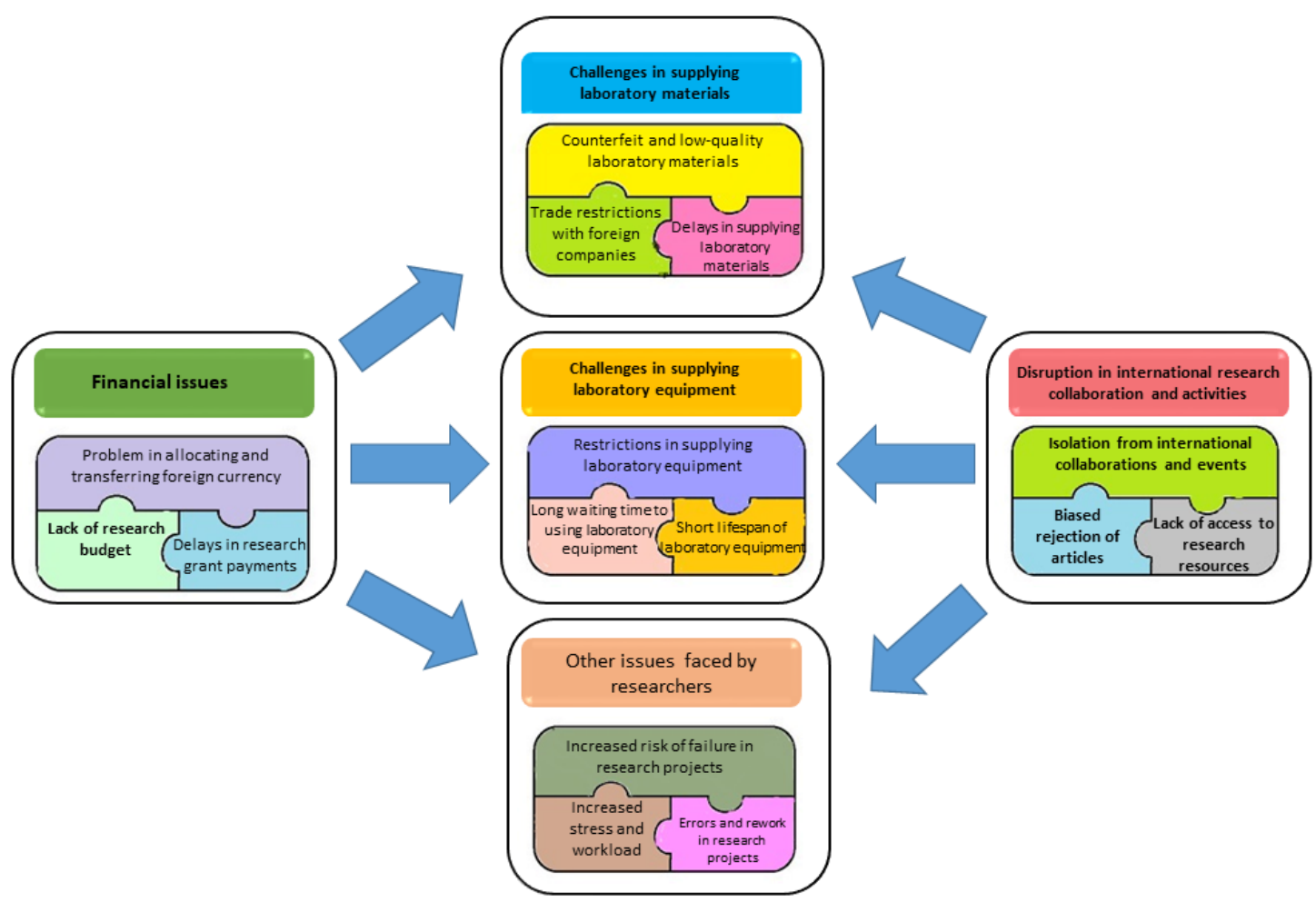

Figure 1. Problems Caused by US Sanctions in Iran's Health Research System.

dollar is difficult or in most cases, impossible...".

Another issue is the lack of cooperation between Iranian supply companies and medical research centers. Most Iranian companies may no longer see it as profitable and easy to supply laboratory materials for medical research centers. This problem is evidenced in the following statement: "... In the past, companies used to bring catalogs to research centers and payments were due at least six months after the delivery of materials; but after the sanctions, the payment should be made first, and materials are delivered several months later....".

\section{Counterfeit and Low-Quality Laboratory Materials}

Counterfeit, fake and low-quality materials are increasingly growing in the health market due to lack of access to original materials. The following statements illustrates this issue: "I bought a salt ion for my research; it didn't solve in the solvent material... we have to analyze whatever we buy before using them to make sure that they are not fake...".

Low quality laboratory materials may consequently affect (the quality of) health research projects. A participant said, "sometimes the quality of the materials is questionable, in which case we have no choice other than either abandoning the project or postponing it until when we can buy original and high-quality materials".

C. Challenges in Supplying Laboratory Equipment Restrictions in Supplying Laboratory Equipment

Foreign companies are concerned about being affected by the US sanctions if they sell (medical) laboratory equipment to Iranian companies. Financial issues have also made it challenging to upgrade medical laboratory equipment. Many participants were concerned about not being able to use new and modern equipment in their research projects. A researcher mentioned that "the devices that are in other countries even in our region are not available in our research centers... in some cases, these devices date back to 20 years ago".

\section{Short Lifespan of Laboratory Equipment}

The costs of laboratory equipment, repairs, maintenance and calibration and workload have increased in health research centers. Consequently, the lifespan of laboratory equipment has decreased. A study participant pointed to this issue: "Foreign companies do not help in servicing laboratory devices". Another participant explained that " $a$ special pipe in one of our devices is broken and the device has been out of order for 6 months".

\section{Long Waiting Times for Using Laboratory Equipment}

The challenges explained in the previous sections have increased the waiting times for using laboratory equipment in Iranian health research centers. The following statements illustrate this issue: "I have been waiting for three months to use a device, then they say it doesn't work properly or is broken". "If the device breaks, we'll have to wait for a long time for it to be fixed with our own research grant". "One thing you could do in a week now takes three months to do". 
D. Other Issues Faced by Researchers

\section{Increased Stress and Workload}

The unsustainable economic conditions and not having access to medical materials and equipment have all increased the stress and workload of Iranian researchers: "look, it takes six months to receive the grant money for research projects... look my device is in such a state, it's broken ... there is a lot of stress and pressure on me as a student". Some disciplines, such as nuclear science, are totally boycotted by the US sanctions. A researcher said, " $m y$ research was related to nuclear medicine, I had no choice other than changing my research area because of not having access to the materials I needed". Another participant said, "I needed a material related to nuclear physics, I couldn't find it and had to abandon this part of my project".

Increased Risk of Failure in Research Projects

The issues caused by sanctions have led to the increased risk of failure in medical and health-related research projects. A doctoral student stated, "some of my friends made changes to their research in the middle of the work because they didn't have access to the laboratory materials on time ...". Another doctoral student said, "I have been a Ph.D. student for 6 years now, why? Because one day there is no money, one day the machine is broken, one day there is no kit ... so, what am I supposed to do?!".

\section{Errors and Rework in Research Projects}

Some participants pointed to 'errors and rework' in research projects due to the low quality materials, uncalibrated laboratory equipment, and the long waiting times for using equipment. Rework, for example, happens when "researchers realize the substance they are using is counterfeit, then they have to do all the research phases again".

E. Disruption in International Research Collaboration and Activities

\section{Isolation from International Collaborations and Events}

The presence of Iranian researchers in international scientific events has decreased significantly, mainly due to the difficulty in issuing visas and the devaluation of the national currency. Iranian (medical) universities and health science researcher are not able to financially support the costs of attending international events like conferences.

The opportunities for studying and doing research abroad have also decreased in recent years. A doctoral student in this study mentioned that "after these sanctions, getting visa from many countries has become like a dream, now you say why don't you attend international conferences?".

Sanctions have also reduced the willingness of international scholars to cooperate with Iranians scholars and students. Interviewees also pointed to the difficulty of receiving health-related grants from foreign regional or international organizations. It has become more difficult for Iranian researchers to obtain foreign grants because funding agencies are aware that transferring funds to Iran is, in many cases, almost impossible.

\section{Biased Rejection of Articles}

Iranian health science researchers sometimes experience desk rejections without being provided with any rationale by journals, or the journals sometimes make the excuse that the article has not been within the scope of the journal. Sometimes due to banking restrictions with Iran, open access journals are unable to accept papers by Iranian researchers. The following statements by participants explain this issue, "My colleague has been told by a journal his name is similar to a sanctioned person and whether he is the same person??"

\section{Lack of Access to Research Resources}

Due to the sanctions, some foreign research centers and companies do not provide services to Iranian researchers. Most websites, databases and information resources have blocked Iranian IPs. Attending online webinars and registering in online trainings (e.g. Coursera) are automatically prohibited if they recognize that the request is coming from Iran. Iranian health research centers are not able to update or upgrade the software they need to complete their research. A participant said, "We do not have access to a series of websites, because they recognize our IPs and thus wouldn't let us have access to their resources...".

\section{Discussion}

"US economic and financial sanctions are having a devastating impact on Iran's economy-and its researchers" ${ }^{10}$ Based on the findings of the current study, US sanctions have affected the health research system in Iran in a variety of ways. The problems caused by the sanctions were classified into five categories: (a) financial issues, (b) difficulty in supplying laboratory materials and (c) equipment, (d) disruption in international research collaboration and activities, and $(e)$ other issues in carrying out research projects (e.g. increased stress and workload).

Iran's inability to sell oil and the country's financial and economic difficulties have reduced the research budget in the country, which is expected to continue in the coming years. The Central Bank of Iran estimated an inflation rate of $37 \%$ for $2018,{ }^{11}$ which according to expert views could go up between $50 \%$ to $70 \% .^{12}$ Iranian health research centers are highly dependent on the governmental budgets. With the existing economic challenges, funds and research grants are paid to researchers and research centers with delays. The increase in the number of health research centers in Iran in recent years, mainly during the sanctions, has increased financial problems. Health research budgets in non-governmental universities in Iran have also declined sharply. Such challenges would consequently harm research quality in several ways, ${ }^{13}$ for instance, by restricting access to the required laboratory 
materials and equipment. ${ }^{14}$

The results indicated that Iranian researchers are having difficulty in accessing high quality materials and equipment for their research projects. Previous studies have also pointed to the difficulties of supplying laboratory materials during sanctions. ${ }^{15-17}$ Sanctions have mainly restricted the power of purchasing laboratory materials and equipment. ${ }^{18}$ Another major issue is transferring funds for purchasing laboratory materials, ${ }^{7}$ which consequently slows down the completion of research projects.

The high costs of maintenance and regular inspection and calibration of laboratory equipment have reduced the lifespan of medical laboratory equipment. Iranian researchers in health research centers wait for a long time to use medical materials and equipment. Another challenge health science researchers are dealing with is redoing some phases of research projects, - for instance, due to broken laboratory equipment or low-quality materials. This has also increased researchers' workload, stress, and frustrations. Honari pointed out that Iranian researchers are facing high workload and mental pressures during the sanctions period. ${ }^{19}$ Possibly strengthening scientific partnership and cooperation with neighboring (and other) countries and conducting joint research projects among research centers in Iran could to some extent resolve the shortage of medical laboratory equipment and materials.

The sanctions have also caused problems in the acceptance and publishing of articles by Iranian researchers. ${ }^{20,21}$ Some publishers and journals refuse to publish articles by Iranian researchers for various (sometimes) unclear reasons, which is against the Committee on Publication Ethics (COPE). ${ }^{22}$ Other studies have also pointed to the rejection of articles by Iranian scholars in international journals. ${ }^{23}$ Elsevier is one of the publishers that has changed the acceptance rules of articles from sanctioned countries. ${ }^{21}$ Kokabisaghi et $\mathrm{al}^{21}$ noted that some well-known academic publishers in the United States have also refused to accept Iranian manuscripts for the fear of being fined up to $\$ 1$ million by the US Treasury.

Iranian (health science) scholars can no longer easily attend international conferences due to financial and visa issuance problems. Sometimes visas are not issued or are issued too late. ${ }^{7,13,18}$ Some studies have also reported that sanctions and economic problems have led to the immigration of a large number of Iranian scholars and educated people to other countries - a phenomenon known as brain drain. In recent years, Iranian scientists and those with high education have had a good chance of finding reliable jobs in countries such as Canada, Australia, and European countries. ${ }^{24,25}$

Iran has also put tremendous focus on knowledge enterprises in recent years to rely on internal capabilities to mitigate the impact of sanctions. However, the exchange rate fluctuations, problems in international collaborations, uncertainty about future, and trade restrictions have caused some problems for knowledge enterprises. ${ }^{26}$

A major limitation of the study is that its participants were recruited from one of the largest and top-ranking medical universities in Iran. Sanctions may have more impact on smaller medical universities with limited financial resources.

In conclusion, this study explored the experiences and perspectives of Iranian health science researchers about the impact of US sanctions on Iran's health research system. Financial and economic problems in Iran, restrictions in transferring funds, and the disruption in Iran's international relations have all created many challenges for supplying medical laboratory materials and equipment for Iranian health research centers and researchers.

\section{Authors' Contribution}

RF, MD and SAA: Study design. MD and RF: Data collection. SAA, MD and IT: Data analysis. RF and ShA: Study supervision. MD, IT and BM: Manuscript writing. Critical revisions for important intellectual content was done by all authors.

\section{Conflict of Interest Disclosures}

The authors of this article state that there is no conflict of interest.

\section{Ethical Statement}

This study has been approved by the ethics committee in of Tabriz University of Medical Sciences (IR.TBZEDMED.REC.1398.184). This research is the results of a doctoral dissertation which was financially supported by the Research and Technology Deputy at Tabriz University of Medical Sciences.

\section{Acknowledgements}

The authors would like to acknowledge all the students who participated in this study. We also appreciate the Research and Technology Deputy at Tabriz University of Medical Sciences for supporting this project.

\section{References}

1. Aloosh M, Salavati A, Aloosh A. Economic sanctions threaten population health: the case of Iran. Public Health. 2019;169:10-3. doi: 10.1016/j.puhe.2019.01.006.

2. Thompson J, Thränert O. Trump preparing to end Iran nuke deal. CSS Policy Perspectives. 2017;5(4). doi: 10.3929/ ethz-b-000181637.

3. Arya N. Economic sanctions: the kinder, gentler alternative?. Med Confl Surviv. 2008;24(1):25-41. doi: $10.1080 / 13623690701775205$.

4. Kheirandish M, Varahrami V, Kebriaeezade A, Cheraghali AM. Impact of economic sanctions on access to noncommunicable diseases medicines in the Islamic Republic of Iran. East Mediterr Health J. 2018;24(1):42-51. doi: 10.26719/2018.24.1.42.

5. Arie S. Unintended consequences of sanctions against Iran. BMJ. 2013;347:1-2. doi: 10.1136/bmj.f4650.

6. Akhondzadeh S. Research in Iran: Hopes and Disappointments. Avicenna J Med Biotechnol. 2016;9(1):1 .

7. Saeidnia S, Abdollahi M. Consequences of international sanctions on Iranian scientists and the basis of science. Hepat Mon. 2013;13(9):e14843. doi: 10.5812/hepatmon.14843.

8. Shariatirad S, Maarefvand M. Sanctions against Iran and the impact on drug use and addiction treatment. Int J Drug Policy. 2013;24(6):636-7. doi: 10.1016/j.drugpo.2013.04.003.

9. Dehghani M, Akhondzadeh S, Mesgarpour B, Ferdousi R. Design and implementation of a social network for laboratory researchers. Iran Red Crescent Med J. 2020;22(10):1-6. doi: 10.32592/ircmj.2020.22.10.103.

10. Butler D. How US sanctions are crippling science in Iran. 
Nature. 2019;574(7776):13. doi: 10.1038/d41586-01902795-y.

11. Hemmati A, Niakan L, Varahrami V. The external determinants of inflation: The case of Iran. Iran Econ Rev. 2018;22(3):74152. doi: 10.22059/IER.2018.66641.

12. Katzman K. Iran Sanctions. 1st ed. USA: Diane Publishing. 2010.

13. Mehrabi S. International economic sanctions, university life, and global citizenship education: the case of Iran. Cultural and Pedagogical Inquiry. 2014;6(1). doi: 10.18733/C3D30T.

14. Dehghani M, Akhondzadeh S, Mesgarpour B, Ferdousi R. A Tool to Reduce the Problems of Iranian Health Researchers. Iran J Public Health. 2020; 49(12):2441-2. doi: 10.18502/ijph. v49i12.4840.

15. Mozafari M. Iran and science publishing in the post-sanctions era. Lancet. 2016;387(10029):1721-2. doi: 10.1016/S01406736(16)30260-4.

16. Takian A, Raoofi A, Kazempour-Ardebili S. COVID-19 battle during the toughest sanctions against Iran. Lancet. 2020;395(10229):1035. doi: 10.1016/S0140-6736(20)306681 .

17. Yousefi A. Analysis of Razi vaccine and serum scientific institute researchers' viewpoint on impact of foreign sanctions on scientific communications and research activities. 2016;2(1): 27-42. doi: 10.22070/RSCI.2016.467.

18. Bezuidenhout L, Karrar O, Lezaun J, Nobes A. Economic sanctions and academia: Overlooked impact and long-term consequences. PloS One. 2019;14(10):1-24. doi: 10.1371/ journal.pone.0222669.
19. Honari A. Struggles for revival: the Iranian student movement under the 'moderate' government, 2013-2017. In: Barlow R, Akbarzadeh S, eds. Human Rights and Agents of Change in Iran. Singapore: Palgrave Macmillan; 2018:127-41. doi: 10.1007/978-981-10-8824-7_7.

20. Mousavi T, Abdollahi M. A review of the current concerns about misconduct in medical sciences publications and the consequences. DARU J Pharm Sci. 2020;8:359-69. doi: 10.1007/s40199-020-00332-1.

21. Kokabisaghi F, Miller AC, Bashar FR, Salesi M, Zarchi AA, Keramatfar A, et al. Impact of United States political sanctions on international collaborations and research in Iran. BMJ Glob Health. 2019;4(5):1692-98. doi: 10.1136/ bmjgh-2019-001692.

22. Foreign Policy. Sudan Sanctions Deprive 'Whole Nation'of Health Care. 2016. Available from: https://foreignpolicy. com/2016/01/14/sudan-sanctions-deprive-whole-nation-ofhealth-care/. Accessed April 2020.

23. ZahediasI S. Iran and science publishing: an open letter. Lancet. 2013;382(9892):596. doi:10.1016/S0140-6736(13)61693-1.

24. Brent J, Abdollahi M. The major role of toxicology societies in global collaborations-a call to action. DARU J Pharm Sci. 2012;20(11). doi: 10.1186/2008-2231-20-11.

25. Gorji A. Sanctions against iran: the impact on health services. Iran J Public Health. 2014:381-2.

26. Fakhari H, Salmani D, Daraei M. The impact of economic sanctions on the knowledge-based companies in iran (in persian). J Sci Technol Policy. 2013;5(3):1-16. 